\title{
A Study on the Number and Arrangement of the Structures Passing Through the Porta Hepatis in South Indian Population
}

\author{
Estudio sobre el Número y Disposición de las Estructuras que Pasan \\ por la Fisura Porta Hepática en Individuos del Sur de la India
}

Sapna, M."; Surekha D. Shetty ${ }^{*} \&$ Satheesha Nayak B.*

SAPNA, M.; SHETTY, S. D. \& NAYAK, B. S. A study on the number and arrangement of the structures passing through the porta hepatis in South Indian Population. Int. J. Morphol., 33(1):164-168, 2015.

SUMMARY: The porta hepatis of the liver is a very important area surgically. The knowledge of the variations in the structures passing through the porta hepatis might be of great help in reducing the risks of surgery in this area. In the current study 59 livers from South Indian cadavers were observed for the number and arrangement of the structures passing through the porta hepatis. In all the livers the portal vein was posteriormost and the hepatic duct was the anteriormost structure. The hepatic artery and its branches were in between the duct and the vein. The mean weight of the liver was $1.025 \mathrm{~kg}$. The mean length of porta hepatis was $4.825 \mathrm{~cm}$ and the mean breadth was $2.433 \mathrm{~cm}$. The number varied from one to three for the duct and vein but for the artery it was between one and four. In $51 \%$ of livers, only one vein and in $80 \%$ of cases only one duct passed through the porta hepatis. In $56 \%$ of cases two arteries passed through the porta hepatis.

KEY WORDS: Liver; Porta hepatis; Bile duct; Portal vein; Hepatic artery.

\section{INTRODUCTION}

The liver is the largest gland in the human body. It is situated in the upper right quadrant of the abdomen below the right dome of the diaphragm. The inferior surface of the liver contains a deep fissure called porta hepatis. The porta hepatis is about 2 inches long transversely and is devoid of peritoneum. However the margins of the porta hepatis give attachment to the lesser omentum. The porta hepatis is bounded anteriorly by the quadrate lobe and posterosuperiorly by the caudate lobe. The hepatic artery with the autonomic plexus around it and the portal vein enter the liver through the porta hepatis, while the two hepatic ducts and some lymphatics emerge out from the liver through it. In this study, we measured the length and breadth of porta hepatis and studied the structures passing through the porta hepatis with special emphasis on the number and arrangement of the structures in the porta hepatis.

\section{MATERIAL AND METHOD}

At Melaka Manipal Medical College (Manipal Campus) Manipal, the formalin embalmed cadavers are stored in a cold room. After the routine dissections for undergraduate medical students, various organs are stored in stainless steel tanks containing $10 \%$ formalin. We studied 59 livers in store since past 6 years. Approximately $15 \%$ of the livers were from the female bodies and the rest were from the males. The cadavers are from the southern part of India. In this study, the weight of the liver, transverse (length) and anteroposterior (breadth) measurements of the porta hepatis were recorded. The hepatic artery, portal vein and the hepatic ducts were studied with a special interest to note their number and position in relation to each other at the porta hepatis. The specimens with variations of these structures were photographed.

\section{RESULTS}

The formalin embalmed livers weighed between 500 $\mathrm{g}$ and $2500 \mathrm{~g}$, the mean value being $1.025 \mathrm{~kg}$. The length of porta hepatis varied from $2.5 \mathrm{~cm}$ to $8 \mathrm{~cm}$, the mean value being $4.825 \mathrm{~cm}$. The minimum breadth (anteroposterior) of the porta hepatis was $1.25 \mathrm{~cm}$ and maximum breath was $3 \mathrm{~cm}$. The mean value for breadth was $2.433 \mathrm{~cm}$. 
The arrangement of the structures in the porta hepatis was constant. The ducts were anterior; the arteries in the middle and the veins were posterior in the porta hepatis of all the livers studied.

The number varied from one to three for the duct and vein but for the artery it was between one and four. In $51 \%$ of livers, only one vein and in $80 \%$ of cases only one duct passed through the porta hepatis. In $56 \%$ of cases two arteries passed through the porta hepatis.

The following Table I shows the number of structures passing through the porta hepatis.

Porta hepatis of only one liver had two ducts, 2 veins and 2 arteries passing through its porta hepatis. In all other livers other combinations of the ducts and vessels was observed. The table II shows all the combinations observed in the study.

Table I. Shows the number of ducts, veins and arteries passing through the porta hepatis and the frequency of their occurrence.

\begin{tabular}{lcc}
\hline Number of structures & Number of livers & Percentage \\
\hline 1 vein & 30 & $50.8 \%$ \\
2 veins & 26 & $44.1 \%$ \\
3 veins & 3 & $5.1 \%$ \\
1 duct & 47 & $79.7 \%$ \\
2 ducts & 10 & $16.9 \%$ \\
3 ducts & 2 & $3.4 \%$ \\
1 artery & 12 & $20.3 \%$ \\
2 arteries & 33 & $55.9 \%$ \\
3 arteries & 9 & $15.3 \%$ \\
4 arteries & 5 & $8.5 \%$ \\
\hline
\end{tabular}

Table II. Shows various combinations of veins, arteries and ducts passing through the porta hepatis.

\begin{tabular}{lc}
\hline Various combinations & Number of livers \\
\hline 1 vein, 1 artery, 1 duct & 5 \\
1 vein, 2 arteries, 1 duct & 15 \\
1 vein, 3 arteries, 1 duct & 4 \\
2 veins, 1 artery, 1 duct & 7 \\
2 veins, 2 arteries, 1 duct & 10 \\
2 veins, 2 arteries, 2 ducts & 1 \\
2 veins, 3 arteries, 1 duct & 3 \\
2 veins 3 arteries, 2 ducts & 1 \\
2 veins, 3 arteries, 2 ducts & 1 \\
2 veins, 4 arteries, 1 duct & 2 \\
2 veins, 4 arteries, 2 ducts & 1 \\
2 veins, 4 arteries, 3 ducts & 1 \\
3 veins, 2 arteries, 2 ducts & 2 \\
3 veins, 4 arteries, 1 duct & 1 \\
\hline
\end{tabular}

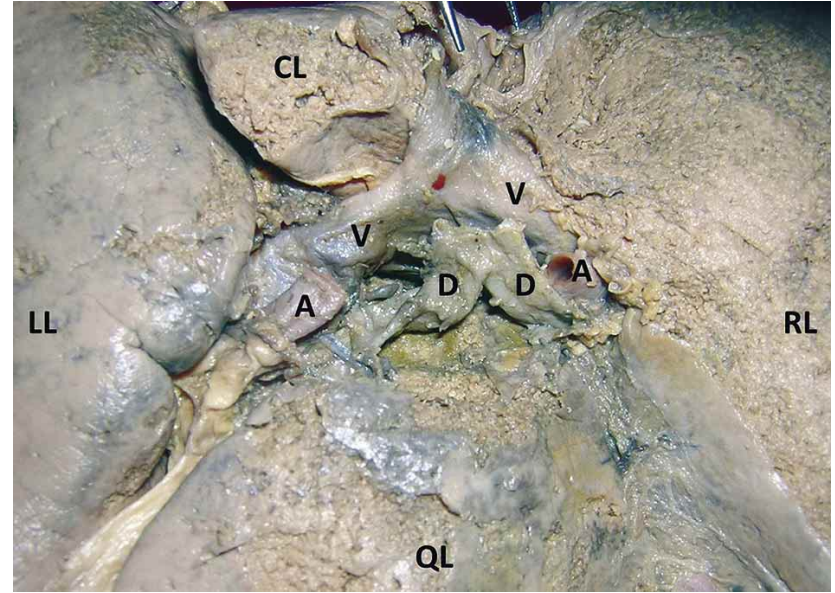

Fig. 1. Porta Hepatis with two ducts, two arteries and two veins. $\mathrm{LL}=$ left lobe; $\mathrm{RL}=$ right lobe; $\mathrm{CL}=$ caudate lobe; $\mathrm{QL}=$ quadrate lobe; $\mathrm{A}=$ artery; $\mathrm{V}=$ vein; $\mathrm{D}=$ duct).

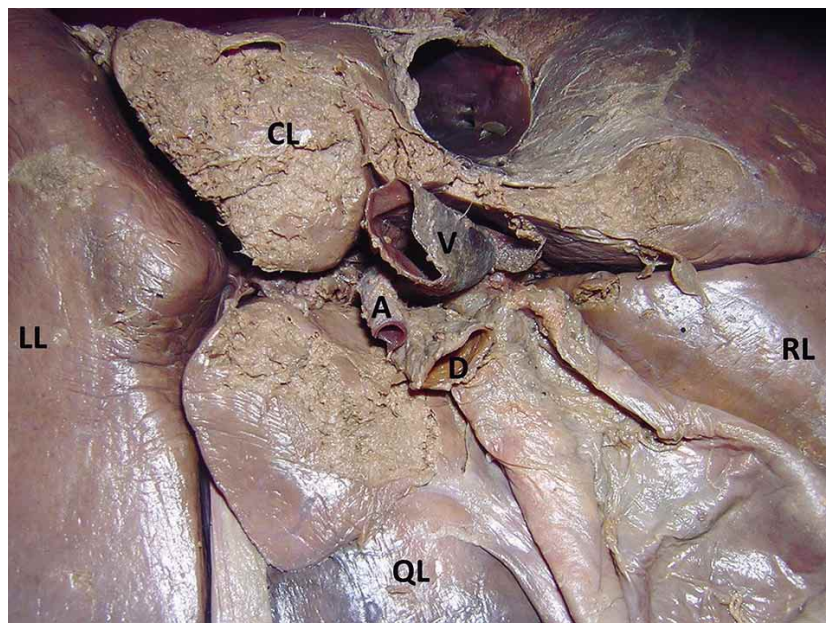

Fig. 2. Porta hepatis with one artery, one vein and one duct. LL= left lobe; $\mathrm{RL}=$ right lobe; $\mathrm{CL}=$ caudate lobe; $\mathrm{QL}=$ quadrate lobe; $\mathrm{A}=$ artery; $\mathrm{V}=$ vein; $\mathrm{D}=$ duct.

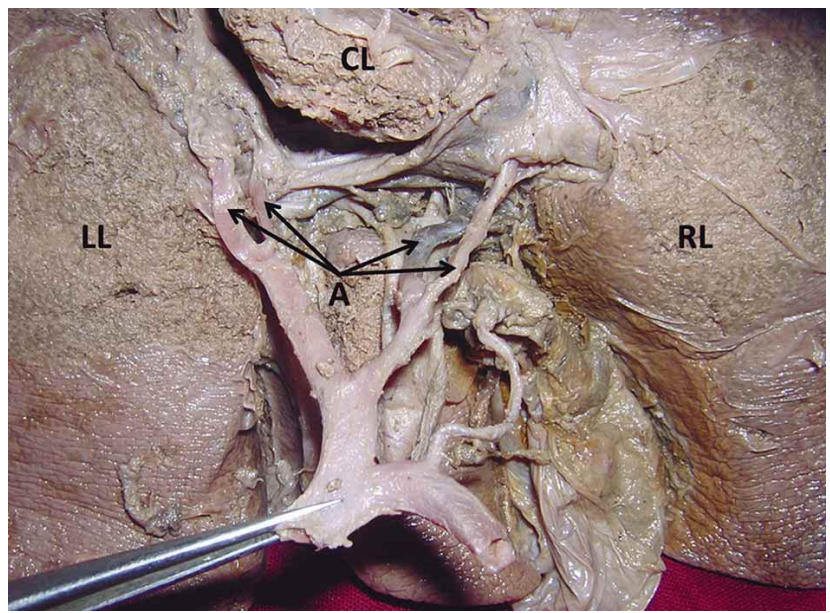

Fig. 3. Porta hepatis with four arteries. $\mathrm{LL}=$ left lobe; $\mathrm{RL}=$ right lobe; $\mathrm{CL}=$ caudate lobe; $\mathrm{A}=$ artery. 


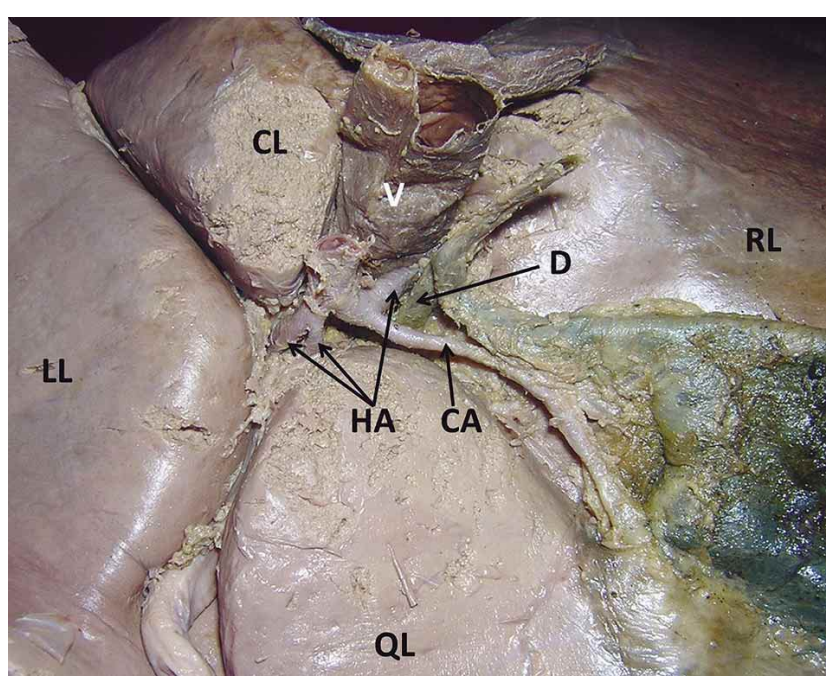

Fig. 4. Porta hepatis with three arteries, one vein and one duct. $\mathrm{LL}=$ left lobe; $\mathrm{RL}=$ right lobe; $\mathrm{CL}=$ caudate lobe; $\mathrm{QL}=$ quadrate lobe; $\mathrm{HA}=$ heatic artery; $\mathrm{CA}=$ cystic artery; $\mathrm{V}=$ vein; $\mathrm{D}=$ duct.

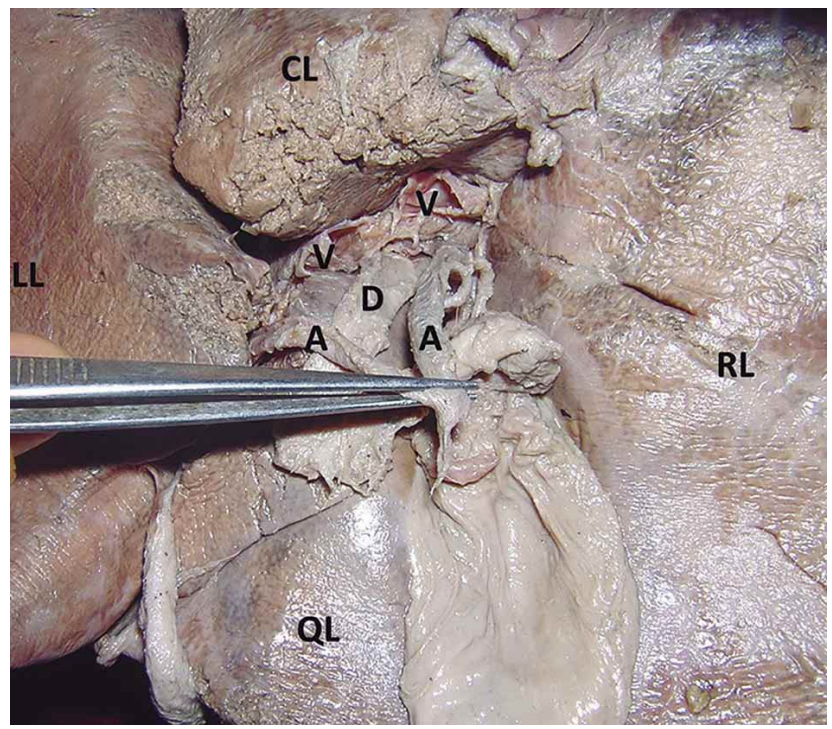

Fig. 5. Porta hepatis with two arteries, two veins and one duct. $\mathrm{LL}=$ left lobe; $\mathrm{RL}=$ right lobe; $\mathrm{CL}=$ caudate lobe; $\mathrm{QL}=$ quadrate lobe; $\mathrm{A}=$ artery; $\mathrm{V}=$ vein; $\mathrm{D}=$ duct.

\section{DISCUSSION}

The number and arrangement of structures in the porta hepatis can vary greatly and it is important for surgeons and radiologists to be informed about the variations. Though there are many studies on the variations of biliary system, hepatic artery and portal vein, the studies on the number and arrangement of the structures at the porta hepatis are lacking. The current study focused on the same issue and attempted to record the various combinations of ducts and vessels at the porta hepatis.
The portal vein is one of the large veins in the abdomen. It is formed by the union of superior mesenteric and splenic veins behind the neck of the pancreas. Normally the portal vein divides into two branches; the left and right branches.

Variants are frequent and account for 20 to $35 \%$ of the population. The most frequent variants are portal trifurcation with division of the main portal vein into the left, right anterior, and posterior branches, and the early origin of the right posterior branch directly from the portal vein. The presence of portal vein variants increases the risk of bile duct hilar anatomical variation. These variants must be diagnosed before complex hepatectomy, split or living donor transplantation, and before complex interventional procedures such as portal vein embolization. In a study by Koc et al. (2007) incidence of overall variations of portal vein was as high as $27.4 \%$. The rate of main portal vein branching variation was $21.5 \%$, right portal vein variation was $3.9 \%$, and segmental portal vein origin traversing the interlobar boundary was $4 \%$. Kouadio et al. (2011) have reported a case of absence of portal vein bifurcation. In the current study, in $51 \%$ of the livers the portal vein did not bifurcate before entering the liver substance. In a study by Chaib (2009) the portal vein trunk divided into right and left branches in $83.3 \%$ of cases and trifurcated in $15.2 \%$ cases. In our study we found bifurcation in $44 \%$ of cases and trifurcation in $5 \%$ of cases.

The portal vein variations might be demonstrated well with routine abdominal MDCT examinations. Most abdominal venous variations are asymptomatic, but awareness of the existence of these variations decreases the complication rates in surgical procedures (Covey et al., 2004; Erbay et al., 2003; Kamel et al., 2001). Knowledge of portal vein variation types enables the recognition of these variations in routine liver imaging. Clinically significant portal vein variations should be noted in routine CT reports.

Variations in the hepatic ducts are also not uncommon. An accurate knowledge of the variations in the hepatic duct confluence is essential for successful living donor liver transplantation. Variants of hepatic duct confluence are frequently involved and injured during major hepatic surgery and seriously complicate postoperatively all patients due to delay of diagnosis and on-going intra-abdominal sepsis. Preoperative imaging of the biliary branching pattern remains the only way to recognize and address properly the problem posed by the variant of biliary anatomy. MRCP offers a reliable and non-invasive visualization of the biliary tree in a manner for the surgical approach to be planned and adapted to prevent an injury of a variant of the hepatic duct confluence. A magnetic resonance 
cholangiopancreatography (MRCP) study by Düsünceli $e t$ al. (2004) has reported the variations of hepatic ducts. In their study anatomic variations at different levels of biliary tree were found in $24.2 \%$ of patients. MRCP showed an aberrant right hepatic duct in $4.8 \%$; a right posterior hepatic duct in $5.7 \%$ and trifurcation of the duct in $0.8 \%$ of patients. Kostov \& Kobakov (2011) have found variation of hepatic ducts in $27.8 \%$ cases. Ohkubo et al., (2004) have reported the absence of right hepatic duct in $26 \%$ of cases and absence of left hepatic duct in $2 \%$ of cases.

The common hepatic artery is a branch of coeliac trunk. It divides into hepatic artery proper and gastroduodenal artery. The hepatic artery proper passes through the right free margin of lesser omentum and enters the porta hepatis where it divides into a right and left branch. These two branches enter the right and left lobes of the liver through the porta hepatis. Several variations have been reported in the branching pattern of hepatic artery. In a study by Abdullah et al. (2006) variations were observed in $31.9 \%$ of hepatic arteries. Gruttadauria et al. (2001) encountered hepatic artery anomalies in $42 \%$ of cases. In their study, the most common anomaly was an accessory right hepatic artery arising from the superior mesenteric artery in $15 \%$ of cases. In a study conducted by Jones \& Hardy (2001) the right hepatic artery arose from superior mesenteric artery in $17 \%$ of cases and from gastroduodenal artery in 6\% of cases. Covey et al. (2002) did and extensive study on hepatic arteries. They report variations of right hepatic artery in 15\% of individuals. There was an accessory right hepatic artery in $2.5 \%$ of cases in their study.

Our study was confined only to the porta hepatis region and in finding the number and arrangement of the structures in this region. So we are not able to mention the source of origin of those additional vessels that passed through the porta hepatis. This study highlights the various possible combinations of the structures at the porta hepatis and it might be of use for the radiologists and surgeons dealing with this region.

SAPNA, M.; SHETTY, S. D. \& NAYAK, B. S. Estudio sobre el número y disposición de las estructuras que pasan por la fisura porta hepática en individuos del sur de la India. Int. J. Morphol., 33(1):164-168, 2015.

RESUMEN: La fisura porta hepática del hígado es un área quirúrgica muy importante. El conocimiento de las variaciones en las estructuras que pasan a través de la fisura porta hepática puede ser de gran ayuda para reducir los riesgos de la cirugía de esta región. En el presente estudio se observaron 59 hígados procedentes de cadáveres del Sur de la India, en relación al número y disposición de las estructuras que pasan a través de la fisura porta hepática. En todos los hígados, la vena porta hepática fue el elemento más posterior y el conducto hepático común el más anterior. La arteria hepática y sus ramas se ubicaban entre el conducto hepático común y la vena porta hepática. El peso medio de los hígados fue $1,025 \mathrm{~kg}$. La longitud media de la fisura porta hepática fue 4,825 $\mathrm{cm}$ y el ancho medio de $2,433 \mathrm{~cm}$. El número varió de uno a tres para el conducto y la vena. El número de arterias varió entre una y cuatro. En $51 \%$ de los hígados, sólo una vena pasaba a través de la fisura porta hepática y en el $80 \%$ de los casos sólo pasaba un conducto. En el 56\% de los casos, dos arterias pasaban a través de la fisura porta hepática.

PALABRAS CLAVE: Hígado; Fisura porta hepática; Vías biliares; Vena porta; Arteria hepática.

\section{REFERENCES}

Abdullah, S. S.; Mabrut, J. Y.; Garbit, V.; De La Roche, E.; Olagne, E.; Rode, A.; Morin, A.; Berthezene, Y.; Baulieux, J. \& Ducerf, C. Anatomical variations of the hepatic artery: study of 932 cases in liver transplantation. Surg. Radiol. Anat., 28(5):46873,2006 .

Chaib, E. Absence of bifurcation of the portal vein. Surg. Radiol. Anat., 31(5):389-92, 2009.

Covey, A. M.; Brody, L. A.; Getrajdman, G. I.; Sofocleous, C. T. \& Brown, K. T. Incidence, patterns, and clinical relevance of variant portal vein anatomy. AJR Am. J. Roentgenol., 183(4):1055-64, 2004.

Covey, A. M.; Brody, L. A.; Maluccio, M. A.; Getrajdman, G. I. \& Brown, K. T. Variant hepatic arterial anatomy revisited: digital subtraction angiography performed in 600 patients. Radiology, 224(2):542-7, 2002.

Düsünceli, E.; Erden, A. \& Erden, I. Anatomic variations of the bile ducts: MRCP findings. Tani. Girisim. Radyol., 10(4):296303, 2004.

Erbay, N.; Raptopoulos, V.; Pomfret, E. A.; Kamel, I. R. \& Kruskal, J. B. Living donor liver transplantation in adults: vascular variants important in surgical planning for donors and recipients. AJR Am. J. Roentgenol., 181(1):109-14, 2003.

Gruttadauria, S.; Foglieni, C. S.; Doria, C.; Luca, A.; Lauro, A. \& Marino, I. R. The hepatic artery in liver transplantation and surgery: vascular anomalies in 701 cases. Clin. Transplant., 15(5):359-63, 2001. 
Jones, R. M. \& Hardy, K. J. The hepatic artery: a reminder of surgical anatomy. J. R. Coll. Surg. Edinb., 46(3):168-70, 2001.

Kamel, I. R.; Kruskal, J. B.; Pomfret, E. A.; Keogan, M. T.; Warmbrand, G. \& Raptopoulos, V. Impact of multidetector CT on donor selection and surgical planning before living adult right lobe liver transplantation. AJR Am. J. Roentgenol., 176(1):193-200, 2001.

Koc, Z.; Oguzkurt, L. \& Ulusan, S. Portal vein variations: clinical implications and frequencies in routine abdominal multidetector CT. Diagn. Interv. Radiol., 13(2):75-80, 2007.

Kostov, D. V. \& Kobakov, G. L. Six rare biliary tract anatomic variations: implications for liver surgery. Eurasian J. Med., 43(2):67-72, 2011.

Kouadio, E. K.; Bessayah, A.; Valette, P. J.; Glehen, O.; Nloga, J.; Diabaté, A. S.; Garcier, J. M. \& Cotton, F. Anatomic variation: absence of portal vein bifurcation. Surg. Radiol. Anat., 33(5):459-63, 2011.

Ohkubo, M.; Nagino, M.; Kamiya, J.; Yuasa, N.; Oda, K.; Arai, T.; Nishio, H. \& Nimura, Y. Surgical anatomy of the bile ducts at the hepatic hilum as applied to living donor liver transplantation. Ann. Surg., 239(1):82-6, 2004.
Correspondence to:

Satheesha Nayak B.

Professor and Head

Department of Anatomy

Melaka Manipal Medical College (Manipal Campus)

International Centre for Health Sciences

Madhav Nagar, Manipal

Udupi District

Karnataka State, 576104

INDIA

Email: nayaksathish@yahoo.com

Received: 17-09-2011

Accepted: 03-11-2014 